\title{
The Enlightenment of Finnish Pre-service Teacher Education on the Pre-service Training of Chinese Preschool Teachers
}

\author{
Juan $\mathrm{Li}^{1 \text {,* }}$ \\ ${ }^{1}$ Shandong Management University, Ji'nan, Shandong 250357, China \\ *Corresponding author. Email: 340515142@qq.com
}

\begin{abstract}
Finland is in a leading position in the education field worldwide. This research focuses on the theory and practice of pre-service education for preschool teachers in Finland. Through the analysis of its characteristics and the use of beneficial experience for reference, based on the status quo of pre-service training of preschool teachers in China, this research discovers the enlightenment and experience that can be used in the pre-service education of Chinese preschool teachers. From the perspective of comparative education research, under the premise of a reasonable analysis of the educational philosophy, enrollment system, curriculum provision, teaching method, educational practice, etc. of Finnish preschool teachers' pre-service education, it's found that the pre-service education of preschool teachers in China can be improved in many aspects, such as controlling the quality of teachers from the source of students, reforming curriculum and teaching, enhancing teachers' research ability, and deepening educational practice, so as to improve the quality of preschool teacher training and promote the sustainable and stable development of China's education.
\end{abstract}

Keywords: Finland, Preschool teachers, Pre-service education, Enlightenment.

\section{INTRODUCTION}

Education plays a pivotal role in overall national strength. The modern revolution has set off a huge storm in the field of education, and the global education has shown a prosperous development trend. The "Several Opinions of the Central Committee of the Communist Party of China and the State Council on Deepening Reform and Standardizing Development of Preschool Education" pointed out: Preschool education is the beginning of lifelong learning, an important part of the national education system, and an important social welfare undertaking. The Ministry of Education of China has adopted an attitude of increasing the importance of preschool education in the entire education system year by year, trying to better implement overall education from the source of education. However, the

*Fund: This paper is the periodic research results of "Research on Kindergarten Curriculum Construction's Returning to Lifeworld from Phenomenological Perspective" (Project No.: 21SDJ001), a research project for young teachers' education and teaching in Shandong Province in 2021. development of preschool education in China still faces problems such as how to conduct reasonable and effective teacher training, how to build a highquality teacher team, and how to improve the quality of education and teaching.

As a country with a small population, Finland is located in the northern part of Europe. It is not rich in natural resources, but it has the world's leading education level. In the wave of global education competitions, Finland has achieved outstanding results in PISA, among which mathematics, science, and reading as the main assessment items are among the best. This has made the world maintain a considerable degree of attention to Finland's outstanding education system.

As one of the world's education powers, Finland's outstanding educational strength is inseparable from its highly developed and complete teacher training system. Preschool education is at the beginning of the entire education system in Finland. The quality of preschool teachers is directly related to the development of education in the whole country. 
Therefore, its training of preschool teachers in terms of curriculum concept, curriculum provision, implementation intensity and resource investment are very extraordinary. It has rich experience in the concept and practice of preschool teachers' preservice education, which is worth learning.

\section{THE CONCEPT AND PRACTICE OF PRE-SERVICE EDUCATION FOR PRESCHOOL TEACHERS IN FINLAND}

\subsection{The Concept of Pre-service Education for Preschool Teachers in Finland}

The goal of pre-service teacher training in Finland has a very important influence on the determination and perfection of the pre-service education concept of preschool teachers. In Finland, the ultimate goal of the entire teacher training is to train teachers as research scholars who have considerable reserve of scientific theoretical knowledge and can possess middle and upper-level practical and scientific research capabilities in practical operations. That is to say, the trainee is required to act as a psychological counselor and educator based on the status of a teacher. Therefore, its concept of pre-service education for preschool teachers is also very clear, which can be roughly divided into two aspects: On the one hand, it attaches importance to an interactive and cooperative teacher culture, and pays attention to the relationship between teachers' personal growth and social culture; on the other hand, it attaches importance to teachers' learning ability, develops their own observation, reflection, understanding and analysis ability of education and teaching, and promotes teachers' lifelong learning and sustainable development.

\subsubsection{Focusing on Cultivating Teachers' Cooperation Concept on the Basis of the Cognition That Education Is Operated Wholely}

The teacher education of Finnish has a deep understanding of the concepts of cooperation, mutual assistance, and communication, and puts them in a very important position. Its understanding of cooperation can be broadly summarized as: It is not that "cooperation is very important" but "cooperation is inevitable", and cooperation is conducive to solving deeper problems. Finnish cooperation philosophy is based on a macroscopic value, that is, education is a huge social cooperation system that operates as a whole. Generally speaking, as an object of education, a school can not only be connected with the government where it is located, but also can cooperate with students' families. In view of this, if teachers trained by Finnish universities want to deal with many needs in such a large environment, invest in education and teaching in a good state, and achieve good teaching results to the greatest extent, they will inevitably need to clarify their responsibilities through cooperation, collaboration, and communication, and integrate them into social groups as much as possible.

In terms of teacher training, Finland hopes to complete cooperation and mutual assistance under the premise of overall cooperation, so as to provide an indispensable interactive foundation for teachers' professional development, and finally train teachers into research scholars with independent thinking awareness and scientific research and exploration capabilities. In addition, from the perspective of teachers' professional development, teachers need to improve themselves through the collision of ideas generated by social contacts and other group activities, so as to obtain considerable professional development. Due to the continuous development of social education, in order to adapt to the educational needs in the new era, the Finnish national education program is also constantly updated, which means that higher requirements are put forward for teachers' own relevant qualities and abilities. Teachers' own education and teaching methods and the realization of self-worth require a certain degree of innovation. In the process of continuously exploring new methods, teachers need to cooperate fully to increase the universality and scientificity of their teaching methods.

\subsubsection{Taking Lifelong Learning as the Orientation, Focusing on Cultivating Teachers' Research Ability}

In 2017, Finland's requirement for preschool teachers changed from being able to teach after obtaining a bachelor's degree to being able to teach after obtaining a master's degree. Behind the emphasis on high academic qualifications is its strict control of teacher quality on another level. Finland attaches great importance to the high standards and high requirements for teachers, and hopes to improve the quality of preschool education from the source by controlling the quality of teachers. In Finland, the responsibilities of teachers have changed from traditional teaching to freely designing classroom teaching and choosing classroom strategies. In 
addition to the basic responsibilities of answering questions, the teacher group also gives consideration to multiple missions such as problem research and decision-making, mutual cooperation, and real-time communication, which has also played a certain role in promoting the improvement of teachers' research capabilities. It is not difficult to find from the preservice cultivation of curriculum of Finnish teachers that the curriculum provision focuses on the teaching and training of students' research methods. For example, the credits for the Finnish teacher training for bachelor's thesis and master's thesis are as high as 40-50, which occupy a considerable proportion of the credits taken by students. Thesis is one of the curriculum projects that can best reflect the research ability of students. In this process, students' research thinking can be exercised, and the goal of focusing on research and cultivating teachers' research ability can be finally achieved.

At the same time, with the launch of the European "Bologna Process", the Finnish research curriculum is constantly being reformed and improved, and the overall education model has been transformed into a 3-year undergraduate + 2-year postgraduate. Finland's lifelong learning-oriented training of teachers is to lay the foundation for future teachers' independent education and teaching, focusing on reflection and the sustainable development of their own educational work. In the early stage, Finnish teachers' lifelong learning is reflected in continuous further study, moving towards high academic qualifications, paying attention to the acquisition of master's degree or doctor's degree, and in the later stage, they mainly carry out educational research independently. This is conducive to the enhancement of teachers' quality, the improvement of teaching quality and the sustainable development of education and teaching career.

\subsection{The Practice of Pre-service Education for Preschool Teachers in Finland}

As the cornerstone of the entire education system, whether or not education practice can be implemented is directly related to the development of the education process. Finnish preschool teachers' pre-service education attaches great importance to the practical process of integrating theory with practice, and believes that only a close combination of the two can play the most effective role. This view is clearly reflected in its enrollment system, curriculum provision, teaching method, educational practice and other specific practical links, and the implementation effect is significant.

\subsubsection{Enrolment System}

Finnish teacher training mainly relies on various comprehensive universities, and the teaching tasks for teacher training are also mainly designed and overall planned by various institutions. In Finland, teachers have a lofty social status and are respected by people from all walks of life. Teachers in primary and secondary schools are more popular. As a result, there are lots of people applying for teachers, high entrance barriers, a excelsior review and selection process, a low acceptance rate, and high competitive pressure. Finnish educational institutions strictly control the number of students enrolled and strictly select the source of students. The specific selection process can be roughly divided into two stages: Since the enrolment target is mainly high school students, the first stage will evaluate students' examination results and school performance, and students with excellent scores can enter the later selection stage; in the second stage, the enrolment colleges and universities will conduct follow-up interviews with the selected students to observe and inspect the students until the most suitable normal students are selected for admission and study. The assessment content includes subject theoretical knowledge, humanistic psychological test and aptitude test, communication skills, research study, introspection thinking and other multi-dimensional perspectives, in order to fully and accurately measure whether the student has the potential of being a teacher.

\subsubsection{Curriculum Provision}

Finnish educational institutions, especially universities, have a high degree of autonomy. Under the premise of following the overall planning outline of the Ministry of Education, various institutions start from the actual situation in setting up their own curriculums. Under the influence of education reform and the "Bologna Process", Finnish preschool teachers' pre-service education adopts a two-staged model of higher education with 3-year undergraduate bachelor's degree +2 -year master's degree. The curriculum provision is mainly based on the preservice training goals of preschool teachers, with major courses and minor courses as the central courses, supplemented by other related courses such as elective courses, communication and orientation courses. The curriculum provision adopts the credit system with total 300 credits, so that the teacher training can be carried out in an orderly manner. To be specific, the proportion of bachelor's and master's thesis in education major is as high as 40 credits, which shows that Finland attaches great importance 
to research courses. The teaching practice part occupies 20 credits. Part of the education minor courses is multidisciplinary studies in subjects and cross-curricular issues taught in comprehensive school, which accounts for 60 credits. This part of the courses is mainly based on kindergartens. The other part is 60 credits for minor elective courses. In addition, different colleges and universities will appropriately increase foreign language or technology and media ICT and other related courses according to the situation. The choice is relatively loose. They can take the students' personal preferences as the starting point and provide a variety of opportunities for students to learn and conduct related research. Through the multidimensional research-centered high-quality teacher training process, teachers can finally have strong research capabilities. In the future teaching process, they can independently discover valuable educational problems and have a complete education teaching system and education professional concept.

\subsubsection{Teaching Method}

Finland makes use of a high degree of educational autonomy to continuously innovate teaching methods, curriculum materials, and imparting methods, making great progress. Before the innovation, Finnish universities mostly adopted traditional teaching methods, including narration, lectures, examinations, etc. However, with the continuous attention and adjustment to the status of students in the classroom, Finland innovatively uses various teaching methods such as projects, seminars, and teamwork. The technology media is also constantly trying to better integrate into the classroom in order to improve teaching efficiency. Seminars are more common in Finland, and are characterized by collisions of ideas through exchanges and discussions, developing ideas, deepening the impression of knowledge, sorting out knowledge in a different way, and stimulating more possibilities. Project cooperation is also being used more and more widely. It goes beyond individual limitations and achieves the effect of integrating student theory and practice through cooperation between teams and teams, and universities and universities. Finland's diverse teaching makes education truly exude passion and vitality.

\subsubsection{Educational Practice}

Most of Finland's educational practice is organized by the teacher training schools of its major educational institutions. Finland encourages early internships. Due to the different stages of undergraduate and postgraduate, its educational practice also has phase characteristics. The first year of the undergraduate is the initial internship. The main purpose is to enter the surrounding kindergarten units to experience and observe the environment of preschool education, think about its educational methods, and observe educational activities. During this period, it emphasizes that students combine their own theories with kindergarten practice, and think about how to become kindergarten teachers. The second year of the undergraduate is the basic internship, which lasts for seven weeks. At this time, it requires students to formulate practical internship goals and plans based on their own internship status. During this period, there will be tutors from both kindergartens and universities to give professional guidance and teaching evaluation, as well as interspersed with students' self-evaluation and peer evaluation, and a comprehensive summary of the practiced will be made. The third year of the undergraduate is the graduation internship. The entire process of completing the graduation thesis reflects the characteristics of Finland's research-oriented training and is also a final display of the results of students' research learning. During the postgraduate period, two years are both advanced internships. Based on the undergraduate internship, it further improves teachers' ability to observe and reflect on their own work, solve teaching problems independently, think and research innovatively, combine theory with practice, work together as a team, and evaluate the teaching by themselves, so as to help teachers to be qualified for future education and teaching work, and realize the shaping of teachers' personal style of education and teaching.

\section{CHARACTERISTICS OF PRE- SERVICE EDUCATION FOR PRESCHOOL TEACHERS IN FINLAND}

The pre-service education of preschool teachers in Finland continues to develop with the change of the times. Since the 1970s, there have been many largescale changes, and the education model has gradually formed distinctive characteristics.

\subsection{Strict Enrolment and Selection, and Multiple Evaluation Subjects}

The teaching profession in Finland is highly respected by people of the nation and has a high social status. It is popular even for young people. Most students choose education major when they 
apply for higher education. Although the cardinal number of application is large, the number of students enrolled in each university is limited, so the enrolment and selection is very strict, choosing the best form the best. Most colleges and universities adopt an independent enrolment system. In addition to the traditional written test, the selection process also includes interviews, psychology and aptitude tests, trial teaching, interviews, etc. It doesn't use grade as a single standard for measurement, but measures the comprehensive quality of students in an all-round way. In the later stage, students will be assessed through on-campus and off-campus tutor evaluation, self-evaluation, and peer evaluation and other methods, which will fundamentally provide high-quality guarantee for future education teacher training.

\subsection{The Teacher Training System Is Specifically Improved}

At this stage, the pre-service education of preschool teachers in Finland implements phase training: 3 years for undergraduates, and 180 ECTS credits are required; 2 years for postgraduate, and 120 ECTS credits are required. In addition, teachers who already have rich kindergarten education experience can apply for a doctorate to continue their studies. The courses and goals of pre-service education at different stages are different, but the whole is coherent and systematic, specific and perfect.

\subsection{Education Is Research-oriented and the Educational Practice System Is Complete}

Finnish teachers' pre-service education focuses on cultivating teachers as research scholars with considerable reserve of scientific theoretical knowledge and being able to possess middle and upper-level practical and scientific research capabilities in practical operations. It offers educational research courses in the curriculum, focusing on the training and practice of research ability. In addition, Finland's educational internship level is clear and grounded in practice, with a complete system from basic internship to advanced internship.

\section{THE STATUS QUO OF PRE- SERVICE TRAINING OF PRESCHOOL TEACHERS IN CHINA}

As an important part of China's basic education, preschool education has a relatively complete and coordinated education system. However, because people's growing educational needs pose new challenges to preschool education, the pre-service training of preschool teachers in China presents a complicated situation.

\subsection{Enrolment System}

The pre-service training of preschool teachers in China is implemented by educational institutions that offer preschool education majors, including vocational special or technical secondary schools, junior colleges, regular institutions of higher learning and normal schools that offer teacher-training majors, etc., adopting multiple forms of enrolment, such as unified enrolment, independent enrolment, and single enrolment of higher vocational education. The preservice training of preschool teachers includes different levels of training such as junior college students, undergraduates, and postgraduates. In recent years, facing the increasing shortage of preschool teachers, every major university has actively responded to the call of the state, generally increasing the number of students enrolled and expanding the scale of enrolment. However, the number of teachers in relatively economically developed areas such as the eastern coastal areas is saturated. Teachers have emphasized "quality" in enrolment, and the number of enrolment has shown a downward trend. In terms of the gender ratio of preschool teachers applying for examinations and enrolment, influenced by traditional career choices and other social factors, there is a large gap between male and female teachers. In order to cultivate talents in many fields, various institutions encourage the male to actively apply for preschool education majors. Most students love the profession of preschool teachers, so they have a better outlook on children, teachers, and education. However, due to the low entry threshold of some colleges and universities, there are certain deficiencies in the professionalism and ability of the trained personnel.

\subsection{Training Mode}

The pre-service education for preschool teachers in China mainly cultivates excellent teachers with good morals, certain professional knowledge, modern 
concepts, and capable of engaging in health care and education and research in kindergarten institutions, preschool education administrators, and teaching and research talents from other related institutions. "Kindergarten Teacher Professional Standards (Trial)" clearly points out "Kindergarten teachers are professionals who perform the responsibilities of kindergarten education. They need to undergo strict cultivation and training, have good professional ethics, and master systematic professional knowledge and professional skills". The potential training targets of preschool education majors in various institutions include teaching talents and research talents. Due to the different training levels and training objectives of Chinese higher vocational and normal universities and colleges, their pre-service training models are also different. But they basically regard occupation and profession as their key training direction, and take the cultivation, entrance, training, and inspection of kindergarten teachers as an important basis for measuring professional training.

\subsection{Curriculum Provision}

The content of preschool education majors in most institutions focuses on the establishment of educational teaching theories and various professional skills, while focusing on the development of the five major aspects of children. Curriculum projects are complex, and the classroom teaching has a wide horizontal range and low extension degree. Among professional theory courses, preschool hygiene, preschool psychology and preschool pedagogy occupy the main position. Students have limited autonomy in choosing courses. The implementation time, place, and project setting flexibility of curriculum practice is not sufficient.

\section{THE ENLIGHTENMENT OF FINNISH PRE-SERVICE EDUCATION FOR PRESCHOOL TEACHERS TO CHINA}

Finland's excellent performance in the PISA test is inseparable from the support of high-quality teachers, and it also shows its unique insights in education. By learning from the pre-service education of preschool teachers in Finland, it is hoped that China can learn effective experience and enlightenment from it, make up for China's shortcomings in preschool education teacher training, further improve the quality of preschool education in China, and promote the flourishing development of education.

\subsection{Strictly Controlling the Quality of Teachers from the Source of Students}

There are many educational institutions offering preschool education majors in China, with different levels, and the standards and requirements for preschool teacher training are different in each institution. Generally speaking, the enrolment of preschool education majors at the starting point of high school in Chinese colleges and universities focuses on the scores of the written examination of the college entrance examination and focuses on the inspection of scientific and cultural knowledge of students. Some colleges and universities have skill interviews, but they neglect to examine the hidden conditions of candidates (such as students' ideological and moral accomplishment, mental health, views of children, values, motivation for applying for exams, and whether they love the education industry, etc. that directly influence the future education and teaching quality). Therefore, it is necessary to improve the college enrolment and selection system, comprehensively improve the interview link when recruiting, and fully integrate the written examination with the interview. On the basis of the written test, a series of interviews, psychological tests, and aptitude tests in Finland should be used for reference, focusing on controlling the comprehensive quality of students, selecting students suitable for the teaching profession, and fundamentally providing guarantees for teachers from the source of students for the development of preschool education. At the same time, it is necessary to strengthen the training of key colleges and universities, carry out model construction, highlight educational characteristics, publicize educational achievements, and give play to their exemplary and leading role in the training of preschool teachers throughout the country.

\subsection{Starting from the Reform of Curriculum and Teaching Methods, Focusing on the Cultivation of Education, Teaching and Research Capabilities}

The traditional duck-stuffing teaching has been unable to keep up with today's growing educational situation, and the problems in the teaching process have become more complicated. As the leading role of classroom teaching, teachers are bound to shoulder the responsibility of independent research, which also puts forward higher requirements for teacher training. The curriculum provision and teaching methods of Finnish preschool teacher training have a positive guiding effect on the existing preschool education 
professional curriculum and teaching reform in China. Chinese preschool teacher training can adjust the proportion of special courses in the curriculum structure, and dig into the accuracy and breadth of the courses in a vertical direction, so that the disciplines are connected and integrated. Efforts should be made to pay attention to the latest educational research results, grasp the timeliness, and incorporate them into classroom teaching in a timely manner to help future teachers gradually form research awareness and research thinking. On the basis of traditional lectures, it's needed to vigorously innovate education and teaching methods, incorporate multiple methods such as projects and seminars, and enrich the knowledge structure of teachers. It's necessary to strengthen the cultivation of the comprehensive quality of future teachers, endow education with temperature, give humanistic care, and create a good education and teaching atmosphere.

\subsection{Improving the Educational Practice Model and Laying the Roots of Teacher Training in Practice}

Educational practice can enable students to further deepen their understanding of the theory they have learned, apply the theory to practice in the process of discovering and solving problems, and accumulate experience for future practical education and teaching work. Due to the objective reality of the shortage of teachers, insufficient professional internship positions, and the imperfect internship system, China's educational internships have problems such as short period of time, incoherence, lack of opportunities for students to reflect on and improve internships, monotonous internship content, and students' inability to go deep into classroom teaching. Learning from Finland's experience, China's educational internships should be arranged in stages in terms of time arrangement, and enrich students' participation and experience forms in terms of content to give students more opportunities to be exposed to the real education and teaching environment, and select dual tutors from universities and internship institutions to give students scientific and meticulous guidance. It's necessary to improve the evaluation method of educational practice, increase dynamic real-time evaluation, and attach importance to the accumulation of students' internship reflection and improvement experience in order to better achieve the purpose of educational practice.

\section{CONCLUSION}

Finnish education has undergone several reforms, and through continuous exploration and practice, a relatively complete teacher education system has gradually formed, which has distinct educational characteristics. It focuses on cooperation and interaction and is research-oriented. The concept and practice of teacher education that adhere to lifelong learning and sustainable development are scientific and forward-looking, playing a leading role in the development of global teacher education. Based on China's national conditions and learning from Finland's experience, China still has a lot of room for development in the enrollment system, training objectives, curriculum provision, and training model of preschool teachers' pre-service education: It can improve the status quo of pre-service education for preschool teachers in China in many aspects, such as controlling the quality of teachers from the source of students, carrying out curriculum and teaching reform, enhancing teachers' research capabilities, deepening educational practice, and integrating preservice and post-service education and so on, so as to improve the quality of teacher training and promote the sustained and stable development of China's education.

\section{AUTHORS' CONTRIBUTIONS}

This paper is independently completed by Juan Li.

\section{REFERENCES}

[1] Chen Daqian. Study on the Pre-service Training Model of Finnish Preschool Teachers [D]. Hunan Normal University, 2018. (in Chinese)

[2] Zhang Nini, Zhao Huijun, Liu Zhongli. The Concept and Practice of Finnish Preschool Teacher Training Courses [J]. Studies In Foreign Education, 2015, 42(04): 45-54. (in Chinese)

[3] Han Dong. Research on Teachers' Pre-service Education in Finland [D]. Huaibei Normal University, 2015. (in Chinese)

[4] Zuo Bing, Fu Xingcong. The Development, Characteristics and Enlightenment of Teacher Education in Finland [J]. Journal of Guangdong University of Education, 2020,40(02): 16-23. (in Chinese)

[5] Li Ling, Zhou Jun. Research on Finnish Preservice Teacher Education Quality Assurance System [J]. Comparative Education Review, 2018,40(10): 84-90. (in Chinese) 
[6] Niemi H, Jakku-Sihvonen R. Teacher education in Finland $[\mathrm{M}] / /$ Zuljan $\mathrm{M} \mathrm{V}$, Vogrinc $\mathrm{J}$. European dimensions of teacher education: similarities and differences. Ljubljana: University of Ljubljana, 2011: 33-51.

[7] Sahlberg P. The most wanted: Teachers and teacher education in Finland [M]. In. DarlingHammond L, Lieberman A. Teacher education around the world: Changing policies and practices [M]. New York, NY: Routledge, 2012: 2-21.

[8] Westbury, I., Hansen, S., Kansanen, P. \& Bjorkvist, O. (2005). Teacher education for research-based practice in expanded roles. Scandinavian Journal of Educational Research, 49(5), 475-485. 